\title{
The Importance Of Accurate Performance Appraisals For Creating Ethical Organizations
}

Rajan Selvarajan, University of Houston, Victoria

Peggy A. Cloninger, University of Houston, Victoria

\begin{abstract}
Improving the day-to-day ethical judgments of employees within an organization remains a challenge. This study examined how employees' job performance outcomes influence how others judge the employees' ethical performance. The research found that respondents judged employees with successful job performance outcomes to have exhibited more ethical behaviors than employees with unsuccessful job performance outcomes. This pattern of results was consistent regardless of the respondent's ethical beliefs. We discuss implications of these results for research and for practice, particularly in terms of improving judgments of ethical behavior in organizations.
\end{abstract}

\section{INTRODUCTION}

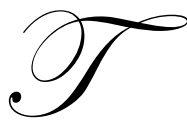

he study of ethical behavior in organizations has been of interest to researchers for decades (e.g., Baumhart, 1961; Brenner \& Molander, 1977; Trevino \& Youngblood, 1990). The recent ethical scandals in major organizations (e.g., WorldCom, Enron, Global Crossing, and Adelphia) have refocused attention on the importance of improving ethical behavior within organizations. Reports of unscrupulous CEOs and top executive officers making millions at the expense of employees and stockholders have led to widespread anger and new legislation in the form of the Sarbanes-Oxley Act to ensure ethical behavior among top management (Stanford, 2004).

Many believe that organizational transformation cannot be externally imposed, however, but must be developed within the organization (Stanford, 2004). Yet the mechanisms for ensuring ethical business conduct are inadequate (Child, 2002). More importantly, although the media may focus on top management, ethical misconduct also is common among rank-and-file employees (Shellenbarger, 2005). Some surveys have found that $60 \%$ of employees who called in sick were not ill and that $12 \%$ of job seekers' resumes contained phony information (Shellenbarger, 2005). Thus, although the importance of top management in creating an environment where ethics can flourish is important, more focus is needed on employees at all levels. Ethical codes and credos are not enough to ensure ethical behavior (Cardy \& Selvarajan, 2006; Stanford, 2004). Organizations need to go beyond the rhetoric of ethics and need to create organizational systems that encourage the ethical behavior of employees.

\section{PERFORMANCE APPRAISALS, GENDER, AND PERSONAL BELIEFS}

Recently business ethics researchers have recommended that organizations explicitly incorporate ethical behavior into performance appraisals in order to improve employee ethical behavior (Buckley, 2001; Weaver, 2001). Incorporating ethical dimensions into the formal performance appraisal systems has been suggested as a way to integrate ethical expectations into employees' formal role identities, and to make ethical behavior at work relevant and rewarding for employees. From a cognitive psychological perspective (e.g., Neisser, 1967; Cardy, Anderson \& Evans, 1991), people may be more likely to judge a worker who achieves excellent work outcomes, that is a positive job appraisal, as successful in other cognitive categories. In other words, if a worker receives a positive performance appraisal, people may tend to rate the worker's ethical behavior more favorably which is fine if the 
worker's behavior was indeed highly ethical. Otherwise, the result could be inordinately positive judgments of the ethical nature of the worker's job behaviors. Yet, there is relatively little empirical evidence examining the influence of job appraisals on ethical judgment. To better understand the influence of job appraisals on ethical judgment, the authors are conducting studies examining the influence of job appraisals on the ethical judgments of employees. Here we present the influence of job appraisals on ethical judgments, and the effect of employee gender and personal ethical beliefs, two variables also hypothesized to influence ethical judgments.

Gender has been a highly studied demographic variable in the ethics field (Roxas \& Stoneback, 2004; Ford \& Richardson, 1994), and the ethical decision making of men versus women continues to be one of the most important areas of research (Loo, 2003). Although women often have been found to be more ethical than men (e.g., Ritter, 2006; Glover, Bumpus, Sharp \& Munchus, 2002), research remains mixed (McCabe, Ingram, \& Dato-on, 2006; O'Fallon \& Butterfield, 2005; Roxas \& Stoneback, 2004) and the differences in the day-to-day ethical judgments of men and women are not well understood. In particular, relatively little research in the ethical domain has directly addressed biases in the ethical decision making of men and women.

Personal characteristics also have been recognized in the appraisal literature as potentially important influences on ratings (e.g., Cardy \& Kehoe, 1984; DeCottis \& Petit, 1978; Lee 1988). In particular, individuals may differ in their internal standards for identifying behavior as ethical or unethical based upon their personal beliefs. People with stronger ethical beliefs may be less influenced by positive or negative job appraisals.

This research is important for both theory and practice. Most theoretical work has proposed assorted variables that influence ethical behavior or has consisted of models of determinants of ethical behavior (e.g., Akaah \& Lund, 1994; Trevino, 1986). Relatively little research in the ethical domain has directly addressed ethical performance and measurement (e.g., McCabe, Ingram, \& Dato-on, 2006; O’Fallon, \& Butterfield, 2005). Whether or not performance appraisal effectiveness influences employee judgment is of particular interest (Jelley \& Goffin, 2001; Uggerslev \& Sulsky, 2002; Cardy \& Dobbins, 1994). The day-to-day ethical judgments of employees are not well understood and the extent to which judgments of ethical performance might be subject to systematic biases such as successful job appraisals has not yet been empirically addressed. This research has important implications for building ethical organizations and for incorporating ethical behavior into performance appraisals.

\section{METHODOLOGY}

The sample consisted of one-hundred-and-eighty full time employees (96 women and 84 men). The average work experience was 8.8 years, and the employees were working in a wide range of organizations from large firms employing more than 1000 employees to smaller firms employing less then 100 and in diverse industries. Each employee was randomly supplied with one of four vignettes describing the performance of a fictitious salesperson. In each vignette the fictitious salesperson was described as a high or low performer, that is, a star performer who consistently exceeded all performance targets or a dismal performer who never achieved performance targets, and summary statements of performance were drawn from the dimensions of sales performance (salesmanship, product knowledge, and ability to initiate/ utilize sales innovations) identified from the research of Bush, Bush, Ortinau, and Hair (1990) and Lucas (1985). Each vignette also included 10 critical incidents that described the fictitious salesperson as ethical or unethical. An ethical salesperson had ethical incidents and an unethical salesperson had unethical incidents (e.g., bribery, deception, padding expense accounts) based on the research by Newstrom and Ruch (1975) and Akaah and Lund (1994). In other words, respondents received a description of one of the following fictitious salespersons: an ethical high performer, an unethical high performer, an ethical low performer, or an unethical low performer.

Respondents were instructed to read the vignette they received and to complete the questionnaire without looking back to the vignette. The questionnaire consisted of one Likert 7-point global ethical rating scale, one Likert 7-point global performance rating scale, and a 12-item behavioral observation scale noting whether or not the sales person had exhibited a specific behavior. Observational ratings are the judgments of the respondents as to whether a behavior occurred. Signal detection measures utilize hit rates and false alarm rates as a means of indicating the accuracy of rater judgments. Ten of these items represented the 10 critical incidents provided in the vignette. Two 
items served as "lures" to calculate false alarm rates. This scale is used for calculating the dependent measure of "bias" in this research, that is, the influence of the appraisal. Bias refers to a subject's tendency to over or under attribute behaviors to the target person, in this research, the fictitious salesperson. Signal detection measures have been used extensively in determining judgment accuracy (e.g., Larson, Lingle \& Scerbo, 1984; Snodgrass \& Corwin, 1988; Sulsky \& Day, 1992). In this study the bias index introduced by Snodgrass and Corwin (1988) is most relevant since the concern is with directional error. That is, we are interested in knowing whether the respondent tended to err toward judging the fictitious salesperson as ethical or unethical. Lastly, respondents also completed demographic data and a 16-item, 7-point Likert scale developed by Daniel, Elliot-Howard, and Dufrene (1997) to measure individual differences in the respondents' ethical beliefs (personal integrity issues, corporate integrity issues, individual rights issues, environmental issues, and international issues). Gender would be used to test for any differences between male and female respondents and ethical beliefs this would be tested as a potential moderating variable. The alpha reliability for the 16 -item scale of ethical beliefs in was 0.77 for the sample.

\section{RESULTS}

Table 1 shows mean scores for bias scores for different levels of ethics and outcomes. For testing the influence of the levels of outcomes on the ethical judgment bias, we used the Kruskal-Wallis test since the variables were not continuous. The test indicated that the influence of outcome on bias was statistically significant (chisquared $=91, \mathrm{p}<0.01$ ). Analysis revealed that job appraisal outcomes bias ethical judgments. The results indicate that bias was more pronounced for the ethical condition than the unethical condition. In other words, the respondents were more influenced by successful performance.

Next, a generalized linear model was used to test whether or not the respondents' own ethical beliefs moderated the findings. The dependent variable for this test is bias which is a continuous variable. Since this variable may not have normal distribution, we used the generalized linear model in the SPSS package version 15.0 that allows testing of models with non-normal distribution of data. The test revealed that the interactions between outcomes and ethical beliefs were not significant. Respondents indicating that they held relatively stronger beliefs did not differ significantly in the ratings of the fictitious sales person than respondents who did not indicate strong ethical beliefs.

Table 2 shows the mean bias scores for men and women. To examine whether or not male or female employees' ethical judgments were influenced differently, we used the Kruskal-Wallis test to determine if the differences in means for the male and female respondents were significant. The results indicate male respondents had significantly higher bias scores than female respondents (Chi-Squared $=78.9 ; \mathrm{p}<0.01$ ) with regards to successful, that is, high performing salespersons. There were no significant differences between male and female respondents with regards to their ratings of unsuccessful salespersons (Chi-Squared $=1.7 ; p>0.05$ ).

\section{CONCLUSION}

Relatively little has been written about how to improve the judgments of employees within the organization. The results of this study provide evidence that job appraisals can support or undermine the ethical judgments of employees. In particular, this study finds that employees, regardless of their personal ethical beliefs, will tend to overlook unethical behavior of another employee if the unethical employee is not punished for these behaviors, but is only rewarded for successful sales performance. In fact, respondents judged a successful fictitious salesperson to have exhibited more ethical behaviors than did unsuccessful fictitious salesperson. The finding that female employees were less biased by successful appraisals speaks well for the potential for organizational diversity as a possible way to improve organizational ethics, and is worthy of additional research. Of potentially greater concern for creating ethical organizations is the finding that the ethical judgments of even more ethically minded employees in the organization are biased by the success of unethical employees.

From a theoretical perspective the findings identify job appraisals as a potential source of systematic bias. This is a notable finding for researchers examining performance appraisals and ethical behavior as well as 
organizational design or cognition. Job appraisals as a source of bias and other variables in addition to employee gender, personal beliefs such as education, experience, age, etc. should be examined in future research.

From a practical perspective, this research strongly suggests that a manager seeking to build an ethical work place should strive to accurately reward ethical behavior and to punish unethical behavior. If a manager rewards unethical employees, the findings of this research indicate that employees may quickly learn that achieving positive ends, that is, positive sales results for the organization, can excuse unethical means. In other words, rewarding unethical performance with positive job appraisals appears likely to influence other employees to be more accepting of unethical behavior in the workplace, regardless of their personal views, and may lead to a 'success breeds acceptance' organizational culture in which unethical behavior is more widely tolerated. To accurately reward ethical behavior (and punish unethical behaviors), managers may need to seek input from other sources such as workers peers or customers. Managers may not always have the opportunity to observe the behavior of subordinates closely and may rely too heavily on other measures of performance such as sales success.

Another implication of the findings of this study is that a failure to punish unethical behavior and to reward ethical behavior may also undermine other organizational processes such as human resources background checks and tests for honesty. The ethical judgments of respondents who indicated relatively stronger ethical beliefs were also biased and prone to overlook unethical behavior of successful salespersons. In other words, even if the organization hires ethical people, they quickly may be "taught" to overlook unethical behavior if unethical behavior is rewarded with successful job appraisals within the organization. A diverse workforce with female and male employees may decrease this problem, but only slightly.

\section{REFERENCES}

1. Akaah, I.P., \& Lund, D. 1994. The influence of personal and organizational values on marketing professionals' ethical behavior. Journal of Business Ethics, 13, 417-430.

2. Baron, R.M. \& Kenny, D.A. (1986). The moderator-mediator variable distinction in social psychological research: Conceptual, strategic and statistical considerations. Journal of Personality and Social Psychology, 51, 1173-82.

3. Baumhart, R.C. (1961). How ethical are businessmen? Harvard Business Review, 39, 6-9.

4. Brenner, S.N., \& Molander. 1977. Is the ethics of business changing? Harvard Business Review, 55, 57-71.

5. Bush, R.P., Bush, A.J., Ortinau, D.J. \& Hair, J.F. (1990). Developing a behavior-based scale to assess retail salesperson performance. Journal of Retailing, 66, 1, 119-136.

6. Cardy, R.L., \& Dobbins G.H. (1994). Performance appraisal: A consideration of alternative perspectives. Cincinnati, OH: South-Western.

7. Cardy, R.L. \& Kehoe, J.F. (1984). Rater selective attention ability and appraisal effectiveness: The effect of a cognitive style on the accuracy of differentiation among ratees. Journal of Applied Psychology, 69, 589-594.

8. Cardy, R. L. \& Selvarajan, T. T. (2006). Beyond rhetorics and bureaucracy: Using HRM to add ethical value. In Deckop (Eds). Human resource management ethics. Information age publishing. Charlotte, NC.

9. Cardy, R.L., Anderson, J.S., \& Evans K.R. (1991). Judging performance: The impact of behaviors, outcomes and trait inferences. Presented at 1991 Society for Industrial and Organizational Psychology Annual Conference

10. Child, J. (2002). The international crisis of confidence in corporations. Academy of Management Executive, 16(3), 145-147.

11. Daniel, L.G., Elliott-Howard, F.E., \& Dufrene, D.D. (1997). The ethical issues rating scale: An instrument for measuring ethical orientation of college students toward various business practices. Educational and Psychological measurement, 57,3, 515-526.

12. DeCottis, T.A., and Petit, A. (1978). The performance appraisal process: A model and some testable hypotheses. Academy of management review, 21, 635-646.

13. Jelley, R.B., \& Goffin, R.D. (2001). Effects of rater priming and rating scale format on rating accuracy. Journal of Applied Psychology, 86, 134-144. 
14. Larson, J.R., Lingle, J.H., \& Scerbo M.M. (1984). The impact of performance cues on leader behavior ratings: The role of selective information availability and probabilistic response bias. Organizational Behavior and Human Performance, 33, 323-349.

15. Lee, J.E. (1988). The effects of cognitive style on rating accuracy with an overall rating scale. Human Performance, 1: 261-271.

16. Lucas, G.H. Jr. (1985). The relationship between job attitudes, personal characteristics and job outcomes: A study of retail store managers. Journal of Retailing, 61, 35-62.

17. McCabe, A., Ingram, R., \& Dato-on, M. (2006). The business of ethics and gender. Journal of Business Ethics, 64, 2 (March), 101-116.

18. Neisser, U. (1967). Cognitive Psychology. Englewood Cliffs, NJ: Prentice Hall.

19. Newstrom, J. W. \& Ruch, W.A. (1975). The ethics of management and management of ethics, $M S U$ Business Topics, 31,

20. O'Fallon, M.J. \& Butterfield, K.D. 2005. A review of the empirical ethical decision-making literature: 1996-2003. Journal of Business Ethics, 59, 4, (July, Part 2), 375-413.

21. Shellenbarger (2005). How and Why We Lie at the Office: From Pilfered Pens to Padded Accounts. Wall Street Journal, March 24, D1.

22. Snodgrass, J.G., \& Corwin, J. (1988). Pragmatics of measuring recognition memory: Applications to dementia and amnesia. Journal of Experimental Psychology: General, 117, 34-50.

23. Stanford, J.H. (2004). Curing the ethical malaise in corporate America: Organizational structure as the antidote. SAM Advanced Management Journal, 14(3), Summer, 14-21.

24. Sulsky, L.M. \& Day, D.V. (1992). Frame of reference training and cognitive categorization: An empirical investigation of rater memory issues. Journal of Applied Psychology, 77, 501-510.

25. Trevino, L.K. (1986). Ethical decision making in organizations: A person-situation interactionist model. Academy of Management Review, 11 (3), 601-617.

26. Trevino, L.K. \& Youngblood, S.A. (1990). Bad apples in bad barrels: A causal analysis of ethical decisionmaking behavior. Journal of Applied Psychology, 75, 378-385.

27. Uggerslev, K. \& Sulsky, L. (2002). Presentation Modality and Indirect Performance Information: Effects on Ratings, Reactions, and Memory, Journal of Applied Psychology, October 2002, pp. 940-950.

28. Weaver, G.R. (2001). The role of human resources in ethics/compliance management: A fairness perspective. Human Resource Management Review; Vol. 11 Issue 1/2, p113, 22p,

Table 1

Means and Standard Deviations for outcome and ethical manipulations.

(Dependent variable: Bias)

\section{Factor}

Outcome: Unsuccessful

Unethical

Ethical

Mean

Outcome: Successful

Unethical

Ethical

Mean

\section{Mean}

0.39

0.32

0.35

0.59

0.69

0.64
SD

0.19

0.07

0.14

0.17

0.09

0.15
$\mathbf{N}$

35

44

79

49

40

89 
Table 2

Means and Standard Deviations for outcome and Gender.

(Dependent variable: Bias)

Factor

Outcome: Successful

Male

Female

Mean

Outcome: Unsuccessful

Male

Female

Mean
Mean

0.66

0.60

0.63

0.34

0.36

$\mathbf{0 . 3 5}$
SD

$\mathbf{N}$

0.10

49

0.18

0.14

40

79

0.13

42

0.14

0.14
37

89

\section{NOTES}

